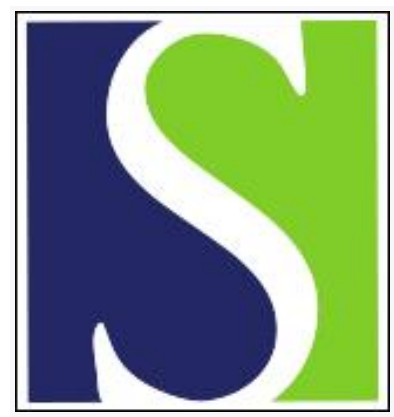

Scand J Work Environ Health 2014;40(2):186-194

https://doi.org/10.5271/sjweh.3393

Published online: 16 Oct 2013, Issue date: 01 Mar 2014

Health, job characteristics, skills, and social and financial factors in relation to early retirement - results from a longitudinal study in the Netherlands

by de Wind A, Geuskens GA, Ybema JF, Blatter BM, Burdorf A, Bongers PM, van der Beek AJ

The relative contribution of different determinants of early retirement is unclear. Especially the financial possibility and the partner's attitude strongly contributed to early retirement, whereas appreciation at work, focus on development and health contributed less. Besides financial incentives, the prolongation of working life might be supported by work-related interventions promoting appreciation, the learning environment, and health.

Affiliation: Department of Work, Health \& Care, Polarisavenue 151, 2132 JJ Hoofddorp, The Netherlands. astrid.dewind@tno.nl

Refers to the following texts of the Journal: 1999;25(2):81-83

2005;31(6):438-449 2013;39(2):125-133 2013;39(2):134-143

The following articles refer to this text: 2015;41(1):24-35;

2015;41(5):421-424; 2017;43(3):234-240; 2019;45(4):346-355

Key terms: ageing; early retirement; employment; financial factor; health; job characteristic; longitudinal study; Netherlands; participation; predictor; relative contribution; skills; social factor

This article in PubMed: www.ncbi.nlm.nih.gov/pubmed/24132500

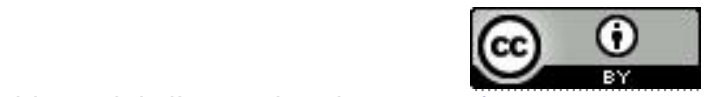




\title{
Health, job characteristics, skills, and social and financial factors in relation to early retirement - results from a longitudinal study in the Netherlands
}

\author{
by Astrid de Wind, MSc, 1,2, 3 Goedele A Geuskens, PhD, ${ }^{2}$ Jan Fekke Ybema, PhD, ${ }^{2}$ Birgitte M Blatter, \\ PhD, ${ }^{2,3}$ Alex Burdorf, PhD, ${ }^{4}$ Paulien M Bongers, PhD, ${ }^{1,2,3}$ Allard J van der Beek, PhD ${ }^{1,3}$
}

\begin{abstract}
de Wind A, Geuskens GA, Ybema JF, Blatter BM, Burdorf A, Bongers PM, van der Beek AJ. Health, job characteristics, skills, and social and financial factors in relation to early retirement - results from a longitudinal study in the Netherlands. Scand J Work Environment Health. 2014;40(2):186-194. doi:10.5271/sjweh.3393
\end{abstract}

\begin{abstract}
Objective This study aimed to investigate the relative contribution of health, job characteristics, skills and knowledge, and social and financial factors to the transition from work to (non-disability) early retirement.

Methods Employees aged 59-63 years (N=2317) were selected from the Study on Transitions in Employment, Ability and Motivation (STREAM) in the Netherlands. Individual characteristics, health, job characteristics, skills and knowledge, and social and financial factors were measured using a questionnaire at baseline. Information on early retirement was derived from the one-year follow-up questionnaire. Logistic regression analyses were used to identify predictors of early retirement. Population Attributable Fractions (PAF) were calculated.

Results Older age [odds ratio (OR) 1.79], poor physical health (OR 1.78), a positive attitude of the partner with respect to early retirement (OR 3.85), and the financial possibility to stop working before the age of 65 (OR 10.2) predicted the transition to early retirement, whereas employees that reported high appreciation at work (OR 0.58$)$ and higher focus on development of skills and knowledge (OR 0.54) were less likely to retire early. PAF were 0.75 for the financial possibility to stop working, 0.43 for a positive attitude of the partner with respect to early retirement, 0.27 for low appreciation at work, 0.23 for a low focus on development, and 0.21 for poor health.

Conclusions The financial possibility to stop working before the age of 65 importantly contributes to early retirement. In the context of rapidly diminishing financial opportunities to retire early in the Netherlands, the prolongation of working life might be promoted by workplace health promotion and disability management, and work-related interventions focusing on appreciation and the learning environment.
\end{abstract}

Key terms ageing; employment; participation; predictor; relative contribution.

In the Netherlands and many other countries, the population is ageing. The ratio of retired elderly to the active working population is increasing, which causes pressure on the social security system. Moreover, a shortage of workers is expected in some sectors, eg, healthcare and the construction industry. To counter the pressure on the social security system and the expected worker shortage in the next decades, it is important that workers prolong their (healthy) working life until or beyond official retirement age. Although the average retirement age in the Netherlands increased from 61 years in 2003 to 63.1 years in 2011 (1), most workers still left work before the official retirement age of 65 in 2011.
In previous research, a variety of factors influencing (non-disability) early retirement have been identified. Van den Berg et al (2) and Schuring et al (3) reported that poor health predicts early retirement (odds, hazard, and risk ratios ranging from 1.2-3.4). High physical work demands (ie, extreme bending of the neck) predicted early retirement in one study [odds ratio (OR) 6.8], but no significant effect of high physical work demands has been found in other studies (OR ranging from 0.9-1.1) (2). High work pressure may also increase the likelihood of early retirement [hazard ratio (HR)1.1] (2). A qualitative study showed that organizational changes, including restructuring and continuous changes in the way work needed to

1 Department of Public and Occupational Health, the EMGO+ Institute for Health and Care Research, VU University Medical Center, Amsterdam, The Netherlands.

2 Netherlands Organisation for Applied Scientific Research TNO, Hoofddorp, The Netherlands.

3 Body@Work, Research Center on Physical Activity, Work and Health, TNO-VU/VUmc, Amsterdam, The Netherlands.

4 Department of Public Health, Erasmus MC, University Medical Center Rotterdam, The Netherlands.

Correspondence to: Astrid de Wind, TNO, Department of Work, Health \& Care, Polarisavenue 151, 2132 JJ Hoofddorp, The Netherlands. [E-mail: astrid.dewind@tno.nl] 
be done, and a poor social climate at work influenced the process towards early retirement as well (4). In addition to health and job characteristics, social factors may play a role in early retirement. Lund et al (5) found that having a partner increased the likelihood of early retirement (OR 2.8). A Dutch study found that support of the partner to continue working was associated with retirement at an older age (6). Besides this, skills and knowledge may influence early retirement. Provision of and participation in education and training was associated with a reduced intention to retire early and actual retirement behavior (7, 8 ). Moreover, colleagues' limited use of one's skills and knowledge may decrease motivation to work and result in early retirement according to qualitative research (4). In a longitudinal investigation, Fischer \& Sousa-Posa (9) showed that pension systems offering more generous retirement options were associated with higher rates of early retirement. The previously mentioned qualitative study added that financial factors may shape a precondition to make the transition from work to early retirement among many employees (4). Hence, factors in the domains of health, job characteristics, knowledge and skills, and social and financial factors may push or pull workers from work to (non-disability) early retirement.

Although previous studies have provided insight into determinants of early retirement, these studies mostly focused on a limited set of determinants. Few studies address the importance of health and job characteristics relative to skills and knowledge, and social and financial factors. This is of interest because it provides insight into what interventions or regulations would (potentially) yield the greatest effect on the prolongation of working life. Moreover, the role of individual characteristics, such as mastery and life events, has barely been studied. Mastery refers to the degree to which persons feel that they are in control of matters that affect their lives (10) and has previously been associated with retirement adjustment (11). With respect to life events, qualitative research showed that employees who were confronted with the finiteness of life sometimes retired early to spend more time with family and friends, or spend more time on hobbies (12).

Therefore, the aim of the present study is to investigate the relative contribution of individual, health, and job characteristics, skills and knowledge, and social and financial factors to the transition from work to (nondisability) early retirement.

\section{Methods}

\section{Study population}

The study population consisted of participants of the Study on Transitions in Employment, Ability, and Moti- vation (STREAM) (13). STREAM is a longitudinal study among 15118 employees, self-employed persons, and persons without paid employment aged 45-64 years. The study population was stratified by age and employment status. STREAM consists of four yearly measurements in October and November of 2010, 2011, 2012, and 2013. In total 12055 employees participated at baseline. In the present study, we used data from the first two waves of STREAM since data from the third and fourth wave were not available yet.

Inclusion criteria for the present study were: (i) employee at baseline and (ii) age 59-63 years. We chose 59 years as a lower age limit, since the proportion of employees that had retired early after one year strongly increased from this age onwards. We chose 63 years as the upper age limit at baseline because the official retirement age in The Netherlands was 65 years in these persons, and, hence, participants had not yet reached the official retirement age at one year follow-up.

Persons who received a disability pension or unemployment compensation at baseline or follow-up were excluded from the present study. Previous studies suggested that different factors and processes underlie the transition from work towards disability pension or unemployment (14).

\section{Measurements}

Participants completed an online questionnaire at baseline and at one-year follow-up. All independent variables were derived from the baseline questionnaire and the outcome variable "early retirement" was derived from the follow-up questionnaire.

\section{Outcome}

Information on early retirement was derived from a question on employment status. In this study, early retirement referred to employees who retired before the official retirement age of 65 years and did not receive disability compensation (ie, non-disability early retirement). This definition excluded persons who reported being both retired and working, and, hence, those who continued working after retirement $(\mathrm{N}=170)$.

\section{Individual characteristics}

Information on age, gender, and educational level was available. Educational level was measured using a question on the highest level of education completed with a diploma, and categorized into low (primary school, lower and intermediate secondary education, or lower vocational training), intermediate (higher secondary education, or intermediate vocational training) or high (higher vocational education or university). 
Mastery was measured using the Pearlin Mastery Scale, which reflects the degree to which persons feel they are in control of matters that affect their lives (10), eg, "I have little control over things that happen to me". This scale consists of seven items with a 5-point answering scale ranging from "totally disagree" to "totally agree" (Cronbach's alpha 0.84).

Apart from that, the following life events in the past 12 months were assessed: got a serious illness, death of a partner, death of a close family member or friend, partner got a serious disease, and close family member or friend got a serious disease. In the analyses, we distinguished between persons who reported at least one of these life events and persons who did not.

\section{Health}

Perceived health was measured using the physical component summary scale (PCS) and the mental component summary scale (MCS) of the Short Form-12 Health Survey (15). The scales range from $0-100(0=$ worst and $100=$ best possible health status). An example of an MCS item is: "Have you felt downhearted and blue?" An example of a PCS item: "Does your health now limit you in climbing several flights of stairs?" Due to the skewed distribution of both scales, the interquartile range $\left(25^{\text {th }}\right.$ $75^{\text {th }}$ percentile) was used to distinguish between poor, moderate, and good health.

\section{Job characteristics}

Physical load was measured using a scale consisting of six items on regular use of force, the use of vibrating tools, awkward postures, prolonged standing, and prolonged squatting based on the Netherlands Working Conditions Survey 2009 (16) and the Dutch Musculoskeletal Questionnaire (17) (Cronbach's alpha 0.86). A 5-point answer scale was used ranging from "always" to "(almost) never". Due to the skewed distribution, the interquartile range was used to distinguish between low, moderate, and high physical load.

Job demands and job autonomy were measured using four and five items, respectively, all derived from the Job Content Questionnaire (Cronbach's alpha 0.87 and 0.78, respectively) $(18,19)$. A 5-point scale was used ranging from "always" to "(almost) never". An example of a job demands is "Do you have to work very fast?". An example of an autonomy item is "Are you able to decide for yourself how to do your work?". Higher scores reflect higher job demands and higher job autonomy.

Restructuring was measured using one item, ie, "Has enterprise restructuring occurred in the past 12 months?" This item could be answered with "No", "Yes, without compulsory redundancies", and "Yes, with compulsory redundancies".
Furthermore, employees separately indicated on a 4-point scale whether appreciation and a good social climate were present at work (20). The answers "not present at all" and "somewhat present" were classified into "not present" and "rather present" and "highly present" were classified into "present".

In addition, social support of colleagues and the supervisor was measured using a 4-item scale derived from the COPSOQ (Cronbach's alpha 0.81) $(21,22)$. Employees indicated how often their colleagues or their supervisor helped or supported them and how often they were willing to listen to their work-related problems, eg, "How often do you get help and support from your immediate superior?". A 5-point answer scale was used ranging from "always" to "almost never". Lower scores reflect higher social support from colleagues and the supervisor.

\section{Knowledge and skills}

Developmental proactivity was measured using a 4-item scale derived from Van Veldhoven \& Dorenbosch (23). This scale reflects the extent to which persons (i) actively search for activities in their job that allow them to expand knowledge and skills and (ii) adapt their knowledge and skills to (future) changes in their jobs, eg, "In my work, I search for people from whom I can learn something". Items could be answered on a 5-point scale ("totally disagree" to "totally agree") and Cronbach's alpha was 0.81 . A higher score means a higher focus on development of skills and knowledge. The same 5-point answer scale was used to assess lack of knowledge by a single item, ie, "I lack 'new' knowledge and skills that have become important due to changes in my work". We categorized the answer options in three groups: no lack of knowledge, neutral, and lack of knowledge.

\section{Social factors}

Persons provided information on their household composition. If a person was married or living together with a partner, the respondent reported the support of this partner with respect to early retirement with one item based on Henkens et al (6), ie, "What would your partner think if you would stop working completely as soon as you get the opportunity?" The response categories were dichotomized into negative / neutral ("very upleasant", "unpleasant" and "not unpleasant, not pleasant") and positive ("pleasant" and "very pleasant").

\section{Financial factors}

The financial situation of the household was measured using the single question "What is the financial situation of your household now?". Employees could choose from the following answer categories: "very short of money", 
"somewhat short of money", "just adequate", "some money left" or "a lot of money left". The categories were classified into "short of money", "just adequate", or "money left".

Furthermore, employees were asked: "Could you financially afford to stop working before the official retirement age?" This question could be answered with "yes", "no", or "don't know".

\section{Statistical analysis}

Descriptive statistics were used to describe the characteristics of the study population. To check whether loss to follow-up was selective, we compared baseline characteristics of non-responders and responders by means of independent T-tests.

Predictors of early retirement (no/yes) were studied by logistic regression analyses. Odds ratios (OR) and $95 \%$ confidence intervals $(95 \% \mathrm{CI})$ were calculated to express the likelihood of the transition from work to early retirement. In the first step of the analyses, univariate associations between individual characteristics, health, job characteristics, knowledge and skills, social factors and financial factors with early retirement were established. Second, multivariate analyses were performed for all variables in the univariate analyses with $\mathrm{P}<0.20$ within each of these domains. Third, multivariate analyses were performed for all variables from the previous step with $\mathrm{P}<0.20$, using stepwise backward elimination. Variables with $\mathrm{P}<0.05$ were retained in the final multivariate model. Age and gender were included in all analyses by default.

OR give information on the strength of the relation between a predictor and early retirement. Since the prevalence of this predictor is not taken into account, OR do not reflect the relative contribution of the predictor to the outcome on population level (24). To estimate the relative contribution of different predictors, population attributable fractions (PAF) were calculated for statistically significant predictors of early retirement in the final multivariate model $(\mathrm{P}<0.05$; except for age). The following formula was used: $\mathrm{PAF}=\mathrm{Pe}(\mathrm{OR}-1) /(1+\mathrm{Pe}(\mathrm{OR}-1))$, whereby $\mathrm{Pe}$ is the prevalence in the study population (25). This formula is meant for dichotomous variables. To calculate the PAF of categorical and continuous predictors in this study, these variables were dichotomized. Their prevalence was calculated and the final multivariate model was run again to obtain the OR to be included in the formula.

Statistical analyses were carried out using SPSS Statistics 20 (IBM Corp, Armonk, NY, USA).

\section{Ethical issues}

The Medical Ethical Committee of the VU University Medical Centre Amsterdam declared that the Medi- cal Research Involving Human Subjects Act does not apply to STREAM. The Medical Ethical Committee had no objection to the execution of this study. In the information for participants that accompanied the online questionnaire, it was emphasized that the privacy of participants was guaranteed, all answers to the questions were treated confidentially, and all data were stored in secured computer systems.

\section{Results}

In total, 2317 persons were included (figure 1). At baseline, compared to participants, persons lost to follow-up reported (i) a slightly higher focus on development of skills and knowledge (3.87 versus 3.81), (ii) more often a worse household financial situation (short of money in $15 \%$ versus $13 \%$, just adequate in $27 \%$ versus $23 \%$, and money left in 59\% versus 64\%), and (iii) more often had no partner (30\% versus $24 \%$ ).

Table 1 shows the characteristics of the study population. In total $11.6 \%$ of the employees made the transition from work to early retirement $(\mathrm{N}=269)$. The correlation between baseline characteristics was small to moderate. Moderate associations were found between a good social atmosphere, the presence of appreciation, and social support of colleagues and the supervisor (Pearson's correlations ranging from $0.34-0.40$ ). Also mastery and mental health were moderately interrelated (Pearson's correlation -0.35). Other variables were only marginally interrelated at baseline (Pearson's correlations $\leq 0.24$ ).

In the univariate logistic regression analyses, older employees and those with a severe life event, poor physical health, a positive attitude of the partner with respect to early retirement, money left in the household and the financial possibility to stop working before the age of 65 years retired more often (table 2). Women and employees with higher job demands, appreciation at work, a good social work atmosphere, higher social support of colleagues and the supervisor, and a higher focus on development of skills and knowledge (ie, developmental proactivity) retired less often.

In the multivariate regression analyses, older age (OR 1.79), poor physical health (OR 1.78), a positive attitude of the partner with respect to early retirement (OR 3.85), not having a partner (OR 1.96) and having the financial possibility to stop working before the age of 65 (OR 10.2) predicted early retirement, whereas employees that reported high appreciation at work (OR 0.58) and higher focus on development (OR 0.54) retired less often. Life events, job demands, a good social atmosphere, social support of colleagues and the supervisor, and the financial situation of the household were not included in the final model (table 2). The influ- 


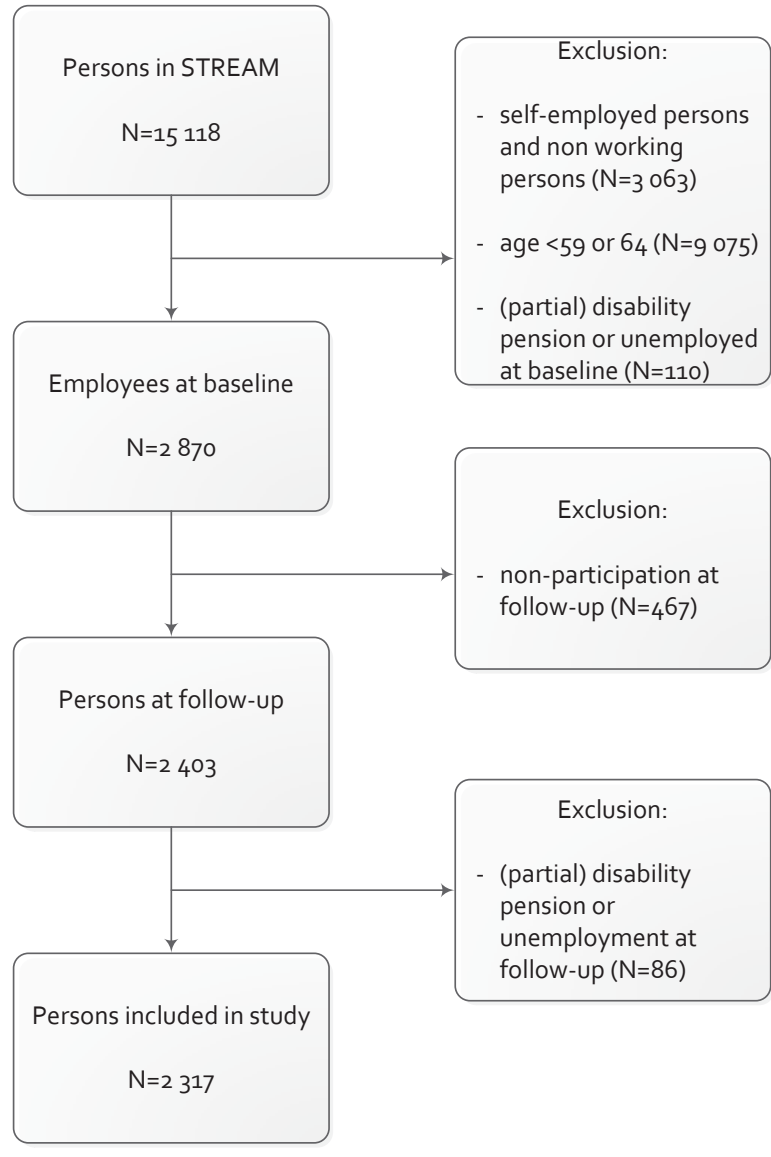

Figure 1. Flow of the study population.

ence of these factors was attenuated in the multivariate (domain) analyses.

Table 3 presents the PAF of the predictors included in the final multivariate regression model of early retirement. The relative contribution was highest for the financial possibility to stop working before the age of 65 (PAF 0.75), followed by a positive attitude of the partner with respect to early retirement (PAF 0.43), absence of appreciation at work (PAF 0.27), a low focus on development of skills and knowledge (PAF 0.23), and a poor physical health (PAF 0.21).

\section{Discussion}

Older age, poor physical health, a positive attitude of the partner with respect to early retirement and the financial possibility to stop working before the age of 65 predicted the transition from work to (non-disability) early retirement, whereas employees that reported high appreciation at work and higher focus on development of skills and knowledge retired less often. Especially the financial pos-
Table 1. Characteristics of study population $(\mathrm{N}=2317)$. [IQR= interquartile range $\left(25^{\text {th }}-75^{\text {th }}\right.$ percentile $\left.)\right]$

\begin{tabular}{|c|c|c|c|}
\hline Characteristics & $\begin{array}{c}\text { Frequency } \\
(\%)\end{array}$ & Mean & IQR \\
\hline \multicolumn{4}{|l|}{ Individual } \\
\hline Age (59-64 years) & & 60.7 & $60-62$ \\
\hline Gender (female) & 41.6 & & \\
\hline \multicolumn{4}{|l|}{ Education level } \\
\hline Low & 31.3 & & \\
\hline Intermediate & 34.1 & & \\
\hline High & 34.6 & & \\
\hline Mastery (1-5) & & 3.8 & $3.4-4.3$ \\
\hline Severe life event (yes) & 35.6 & & \\
\hline \multicolumn{4}{|l|}{ Health } \\
\hline \multicolumn{4}{|l|}{ Physical health } \\
\hline Good (58-100) & 16.9 & & \\
\hline Moderate (48-57) & 56.7 & & \\
\hline Poor (1-47) & 26.4 & & \\
\hline \multicolumn{4}{|l|}{ Mental health } \\
\hline Good (59-100) & 24.2 & & \\
\hline Moderate (52-58) & 50.8 & & \\
\hline Poor (1-51) & 25.0 & & \\
\hline \multicolumn{4}{|l|}{ Work } \\
\hline \multicolumn{4}{|l|}{ Physical demands } \\
\hline Low $(0.0-0.9)$ & 38.4 & & \\
\hline Medium (1.0-2.2) & 38.2 & & \\
\hline High (2.3-4.0) & 23.4 & & \\
\hline Job demands $(1-5)$ & & 2.9 & $2.5-3.5$ \\
\hline Autonomy (1-5) & & 3.9 & $3.6-4.4$ \\
\hline \multicolumn{4}{|l|}{ Restructuring } \\
\hline No & 66.5 & & \\
\hline Yes, no compulsory redundancies & 22.1 & & \\
\hline Yes, with compulsory redundancies & 11.4 & & \\
\hline Appreciation (yes) & 58.1 & & \\
\hline Good social atmosphere (yes) & 81.5 & & \\
\hline Social support (1-5) & & 3.5 & $3.0-4.0$ \\
\hline \multicolumn{4}{|l|}{ Skills / knowledge } \\
\hline Developmental proactivity (1-5) & & 3.8 & $3.5-4.0$ \\
\hline \multicolumn{4}{|l|}{ Lack of knowledge } \\
\hline No & 54.4 & & \\
\hline Yes & 15.4 & & \\
\hline Neutral & 30.2 & & \\
\hline \multicolumn{4}{|l|}{ Social factors } \\
\hline \multicolumn{4}{|l|}{ Partner's attitude to early retirement } \\
\hline Negative / neutral & 40.0 & & \\
\hline Positive & 36.2 & & \\
\hline No partner & 23.8 & & \\
\hline \multicolumn{4}{|l|}{ Financial factors } \\
\hline \multicolumn{4}{|l|}{ Financial situation } \\
\hline Money left & 64.7 & & \\
\hline Just adequate & 23.3 & & \\
\hline Short of money & 12.0 & & \\
\hline \multicolumn{4}{|l|}{$\begin{array}{l}\text { Financially possible to stop working } \\
\text { before age } 65\end{array}$} \\
\hline No & 36.4 & & \\
\hline Yes & 52.7 & & \\
\hline Don’t know & 10.9 & & \\
\hline \multicolumn{4}{|l|}{ Outcome } \\
\hline Early retirement & 11.6 & & \\
\hline
\end{tabular}

sibility to stop working before the age of 65 , the attitude of the partner with respect to early retirement, and appreciation at work strongly contributed to early retirement.

Earlier studies have shown that poor health, workrelated factors, skills and knowledge, and social and financial factors are determinants of early retirement 
Table 2. Predictors of early retirement in logistic regression analyses ( $\mathrm{N}=2317$ ). [OR=0dds ratio; $95 \% \mathrm{Cl}=95 \%$ confidence interval]

\begin{tabular}{|c|c|c|c|c|c|c|}
\hline \multirow[t]{2}{*}{ Characteristics } & \multicolumn{2}{|c|}{ Univariate } & \multicolumn{2}{|c|}{$\begin{array}{l}\text { Multivariate per } \\
\text { domain } \\
\end{array}$} & \multicolumn{2}{|c|}{ Multivariate } \\
\hline & $\mathrm{OR}$ & $95 \% \mathrm{Cl}$ & $\mathrm{OR}$ & $95 \% \mathrm{Cl}$ & $\mathrm{OR}$ & $95 \% \mathrm{Cl}$ \\
\hline \multicolumn{7}{|l|}{ Individual } \\
\hline Age (59-64) & $1.71^{\mathrm{a}}$ & $1.55-1.89$ & $1.72^{\mathrm{a}}$ & $1.55-1.90$ & $1.79^{\mathrm{a}}$ & $1.58-2.01$ \\
\hline Gender (female) & $0.64^{\mathrm{a}}$ & $0.49-0.84$ & $0.61^{\mathrm{a}}$ & $0.46-0.80$ & $0.79^{\mathrm{b}}$ & $0.57-1.09$ \\
\hline \multicolumn{7}{|c|}{ Education level } \\
\hline Low & 1.00 & & & & & \\
\hline Intermediate & 0.83 & $0.60-1.34$ & & & & \\
\hline High & 1.03 & $0.76-1.40$ & & & & \\
\hline Mastery (1-5) & 1.07 & $0.87-1.32$ & & & & \\
\hline Severe life event & $1.22^{b}$ & $0.94-1.59$ & $1.24^{\mathrm{b}}$ & $0.95-1.62$ & & \\
\hline \multicolumn{7}{|c|}{ Health } \\
\hline \multicolumn{7}{|c|}{ Physical health } \\
\hline Good (58-100) & 1.00 & & 1.00 & & 1.00 & \\
\hline $\begin{array}{l}\text { Moderate } \\
(49-57)\end{array}$ & 1.01 & $0.69-1.46$ & 1.01 & $0.69-1.46$ & 0.92 & $0.60-1.40$ \\
\hline Poor $(1-48)$ & $1.37^{\mathrm{b}}$ & $0.91-2.04$ & $1.37^{\mathrm{b}}$ & $0.91-2.04$ & $1.78^{\mathrm{a}}$ & $1.11-2.85$ \\
\hline \multicolumn{7}{|l|}{ Mental health } \\
\hline Good (59-100) & 1.00 & & & & & \\
\hline $\begin{array}{l}\text { Moderate } \\
(52-58)\end{array}$ & 0.95 & $0.69-1.30$ & & & & \\
\hline Poor (1-51) & 0.92 & $0.63-1.33$ & & & & \\
\hline \multicolumn{7}{|l|}{ Work } \\
\hline \multicolumn{7}{|c|}{ Physical demands } \\
\hline Low $(0.0-0.9)$ & 1.00 & & & & & \\
\hline $\begin{array}{l}\text { Medium } \\
(1.0-2.2)\end{array}$ & 1.07 & $0.80-1.44$ & & & & \\
\hline High (2.3-4.0) & 1.13 & $0.81-1.58$ & & & & \\
\hline $\begin{array}{l}\text { Job demands } \\
(1-5)\end{array}$ & $0.87^{\mathrm{b}}$ & $0.75-1.02$ & $0.83^{\mathrm{a}}$ & $0.71-0.97$ & & \\
\hline Autonomy (1-5) & 0.93 & $0.78-1.10$ & & & & \\
\hline \multicolumn{7}{|c|}{ Restructuring } \\
\hline No & 1.00 & & & & & \\
\hline $\begin{array}{l}\text { Yes (no } \\
\text { compulsory } \\
\text { redundancies) }\end{array}$ & 1.05 & $0.77-1.42$ & & & & \\
\hline $\begin{array}{l}\text { Yes (with } \\
\text { compulsory } \\
\text { redundancies) }\end{array}$ & 0.75 & $0.48-1.17$ & & & & \\
\hline $\begin{array}{l}\text { Appreciation } \\
\text { (yes) }\end{array}$ & $0.64^{\mathrm{a}}$ & $0.50-0.83$ & $0.77^{\mathrm{b}}$ & $0.57-1.03$ & $0.58^{\mathrm{a}}$ & $0.43-0.79$ \\
\hline $\begin{array}{l}\text { Good social } \\
\text { atmosphere (yes }\end{array}$ & $0.60^{a}$ & $0.44-0.80$ & $0.76^{\mathrm{b}}$ & $0.54-1.08$ & & \\
\hline $\begin{array}{l}\text { Social support } \\
(1-5)\end{array}$ & $0.74^{\mathrm{a}}$ & $0.64-0.87$ & $0.79^{\mathrm{a}}$ & $0.67-0.93$ & & \\
\hline \multicolumn{7}{|c|}{ Skills / knowledge } \\
\hline $\begin{array}{l}\text { Developmental } \\
\text { proactivity } \\
(1-5) \\
\text { Lack of } \\
\text { knowledge }\end{array}$ & $0.49^{\mathrm{a}}$ & $0.40-0.61$ & $0.49^{a}$ & $0.40-0.61$ & $0.54^{\mathrm{a}}$ & $0.42-0.68$ \\
\hline No & 1.00 & & & & & \\
\hline Yes & 1.07 & $0.74-1.55$ & & & & \\
\hline Neutral & 1.12 & $0.84-1.49$ & & & & \\
\hline \multicolumn{7}{|c|}{$\begin{array}{l}\text { Social factors } \\
\text { Partner's attitude } \\
\text { to early retirement }\end{array}$} \\
\hline $\begin{array}{l}\text { Negative / } \\
\text { neutral }\end{array}$ & 1.00 & & 1.00 & & 1.00 & \\
\hline Positive & $3.66^{\mathrm{a}}$ & $2.65-5.04$ & $3.66^{\mathrm{a}}$ & $2.65-5.04$ & $3.85^{\mathrm{a}}$ & $2.68-5.53$ \\
\hline No partner & $1.49^{b}$ & $0.99-2.22$ & $1.49^{\mathrm{b}}$ & $0.99-2.22$ & $1.96^{\mathrm{a}}$ & $1.25-3.08$ \\
\hline \multicolumn{7}{|c|}{$\begin{array}{l}\text { Financial factors } \\
\text { Financial situation }\end{array}$} \\
\hline Money left & 1.00 & & 1.00 & & & \\
\hline Just adequate & 0.90 & $0.66-1.22$ & $1.44^{\mathrm{a}}$ & $1.04-2.00$ & & \\
\hline Short of money & $0.54^{\mathrm{a}}$ & $0.34-0.88$ & 1.30 & $0.78-2.18$ & & \\
\hline
\end{tabular}

Table 2. continued

\begin{tabular}{|c|c|c|c|c|c|c|}
\hline \multirow[t]{2}{*}{ Characteristics } & \multicolumn{2}{|c|}{ Univariate } & \multicolumn{2}{|c|}{$\begin{array}{l}\text { Multivariate per } \\
\text { domain }\end{array}$} & \multicolumn{2}{|c|}{ Multivariate } \\
\hline & $\mathrm{OR}$ & $95 \% \mathrm{Cl}$ & $\mathrm{OR}$ & $95 \% \mathrm{Cl}$ & $\mathrm{OR}$ & $95 \% \mathrm{Cl}$ \\
\hline \multicolumn{7}{|l|}{$\begin{array}{l}\text { Financially } \\
\text { possible to stop } \\
\text { working before } \\
\text { age } 65\end{array}$} \\
\hline No & 1.00 & & 1.00 & & 1.00 & \\
\hline Yes & $8.82^{\mathrm{a}} 5$ & $5.64-13.80$ & $9.78^{a}$ & $6.15-15.55$ & $10.18^{a}$ & $6.23-16.62$ \\
\hline Don't know & $2.19^{\mathrm{a}}$ & $1.10-4.35$ & $2.25^{\mathrm{a}}$ & $1.13-4.83$ & $3.29^{a}$ & $1.58-6.84$ \\
\hline
\end{tabular}

Table 3. Population attributable fractions (PAF) of factors that significantly predicted early retirement in multivariate logistic regression analyses [OR=odds ratio; $95 \% \mathrm{Cl}=95 \%$ confidence interval]

\begin{tabular}{|c|c|c|c|c|}
\hline Characteristics & $\begin{array}{l}\text { Proportion } \\
(\%)\end{array}$ & $\mathrm{OR}$ & $95 \% \mathrm{Cl}$ & PAF \\
\hline Physical health & & & & 0.21 \\
\hline $\begin{array}{l}\text { Moderate and good } \\
\text { physical health (49-100) }\end{array}$ & 73.6 & 1.00 & & \\
\hline $\begin{array}{l}\text { Poor physical health } \\
(1-48)\end{array}$ & 26.4 & 1.90 & $1.36-2.65$ & \\
\hline Appreciation & & & & 0.27 \\
\hline Present & 58.1 & 1.00 & & \\
\hline Not present & 41.9 & 1.73 & $1.28-2.34$ & \\
\hline Developmental proactivity & & & & 0.23 \\
\hline $\begin{array}{l}\text { High focus on develop- } \\
\text { ment }(3.5-5)\end{array}$ & 80.5 & 1.00 & & \\
\hline $\begin{array}{l}\text { Low focus on develop- } \\
\text { ment }(0-3.5)\end{array}$ & 19.5 & 2.24 & $1.60-3.13$ & \\
\hline $\begin{array}{l}\text { Partner's attitude to } \\
\text { early retirement }\end{array}$ & & & & 0.43 \\
\hline $\begin{array}{l}\text { Negative / neutral or } \\
\text { no partner }\end{array}$ & 63.8 & 1.00 & & \\
\hline Positive & 36.2 & 3.01 & $2.22-4.08$ & \\
\hline $\begin{array}{l}\text { Financially possible to } \\
\text { stop working before } \\
\text { age } 65\end{array}$ & & & & 0.75 \\
\hline No or don’t know & 47.3 & 1.00 & & \\
\hline Yes & 52.7 & 6.78 & $4.56-10.09$ & \\
\hline
\end{tabular}

$(2,3,5,7-9)$. In the present study, the relation between financial factors and early retirement seems relatively strong compared to previous studies $(26,27)$. However, comparison to previous studies is hampered by differences in the aspects of the financial situation assessed and differences in the outcome variables. The relatively strong relationship between the financial possibility to stop working and early retirement compared to other predictors in the present study may (partly) be explained by the short follow-up period of one year. Since retirement is a process instead of a sudden event for many people, some employees may already have known it was financially possible to retire in the months before actual retirement, and hence, at the baseline assessment. It could be 
hypothesized that the shorter the period of time between assessment of financial factors and early retirement, the stronger the association. This is supported by a previous qualitative study that showed that the financial possibility to retire early often becomes important after other push and pull factors towards retirement arise (4). Therefore, we recommend future research to study within one dataset whether the strength of the association between different predictors and early retirement depends on the period of time between the assessment of these variables.

Our finding on the influence of health on early retirement contradicts the results of a recent study, in which Robroek et al (28) found no significant effect of poor health on early retirement. These contradictory results might be explained by the fact that two distinct processes play a role. On the one hand, poor health could result in early retirement among persons who are not able to work at all, or experience a decrease in their ability to work. On the other hand, good health may contribute to early retirement among persons who want to enjoy life as long as their health allows them to do so (12).

As opposed to the review by Van den Berg et al (2), we did not find a significant relation between physical demands and task demands on the one hand, and early retirement on the other hand. This might (partly) be explained by the healthy worker effect. In the review by Van den Berg et al, much younger populations were included ( $\geq 25$ years) than in our study (59-63 years). Our population may be a healthier population, since employees with health problems due to high physical and/or task demands may have dropped out of work before the age of 59. Another explanation might be that some employees who had retired at follow-up, had already planned to do so at baseline and had already reduced their physical and/or task demands.

Our result on the influence of partners supplements the finding that having a partner increases the likelihood of early retirement (5) and that partners' support to continue working positively influences retirement age (6). We obtained insight in the circumstances in which having a partner positively influences the transition from work towards early retirement. It is not so much having a partner that increases the likelihood of early retirement, but having a partner who stimulates such early retirement. Hence, our study endorses the importance of support of a partner in the retirement decision.

To our knowledge, the present study is the first study that investigated a wide range of predictors of early retirement at the same time, and hence, provided insight in the relative importance of different domains. Especially the financial possibility to retire early appeared to be important in the transition from work to early retirement. At the time of the data collection of the present study, early retirement schemes were still widely accessible, which may have contributed to the relatively large PAF for the financial possibility to retire early in our study. Favorable arrangements to retire early will decline in the near future due to changes in the social security system with the official retirement age increasing from 65 in 2012 to 67 in 2023 in the Netherlands (29). This might affect the relative importance of predictors of early retirement addressed in the present study. Moreover, the decline in favorable early retirement schemes might decrease the proportion of persons who leave the workforce through early retirement, but might increase the proportion of persons who leave the workforce via different pathways, eg, disability pensions or unemployment. We would recommend future research to investigate changes in the relative importance of predictors of early retirement and pathways out of employment.

A strength of the present study is that we used longitudinal data, which allowed us to investigate predictors of early retirement instead of associations between early retirement and certain characteristics. Moreover, we studied a broad set of predictors in a diversity of domains and participants performed a broad variety of jobs. However, this study also has limitations. A first limitation is the previously mentioned short follow-up period of one year, which may have influenced baseline measurements and their associations with early retirement. For example, employees who knew they would retire during the next months possibly focused less on the development of new skills, had already reduced their physical and job demands, and knew it was financially possible to stop working. Second, the response of the study was $83 \%$. Although this response is high and differences between respondents and non-respondents were small, bias due to non-response at follow-up cannot be ruled out. Third, due to the large number of predictors we investigated in the present study, there is a risk of overlap between the predictors of interest. To minimize this risk, we performed multivariate domain analyses, and thereby reduced the number of predictors in the final multivariate model. Fourth, in line with Van den Berg et al (14) and Mykletun et al (30), we used OR instead of relative risks to calculate PAF. This may have resulted in some overestimation of the PAF. However, since the sum of the PAF exceeds 1, we would like to point out that the presented PAF should be interpreted only as a measure of ranking the relative importance of different factors rather than an exact estimate of the proportion of workers with early retirement due to a specific predictor. Fifth, all data relied on self-reports since register data were not available. It may be difficult to measure certain job characteristics, such as physical demands (31), by self-report, but previous research showed that subjective health assessments are valid health status indicators in middle-aged populations (32). To our knowledge, no previous study investigated the validity of self-reported employment status. However, for none of the variables 
we have reasons to assume differential misclassification. Sixth, the item measuring the financial possibility to stop working explicitly referred to "retirement", in contrast to other independent variables. This may have contributed to the relatively strong relation with early retirement in addition to the short follow-up period. Seventh, differences between subgroups of employees were not presented due to a lack of statistical power. Additional analyses stratified by gender and educational level did not reveal substantial differences. However, the relation between a positive attitude of the partner with respect to stopping to work and early retirement might be stronger among high- compared to low-educated employees. We recommend future studies with sufficient statistical power to investigate differences between subgroups of workers. Finally, data collection took place at the same time as an extensive public debate on the need to prolong working life in the Netherlands. Employees might have felt obligated to continue working, which might have buffered the relation between the predictors that were studied and early retirement.

In conclusion, our results indicated that especially the financial possibility to stop working before 65 played an important role in the transition from work towards early retirement. On the basis of these results, we expect that the present gradual increase of the official retirement age and constraining the financial possibilities to retire early will indeed contribute to the prolongation of working life. In the context of rapidly diminishing financial opportunities to retire early in the Netherlands, the prolongation of working life may be supported by health-promotion programs in the workplace. Moreover, since more older workers are expected to continue working in spite of chronic health problems in the future, disability management may also gain importance to support extended working careers. Previous reviews have shown that these interventions may positively affect health and work-related outcomes, including absenteeism, presenteeism, and work performance (33, 34). Furthermore, the prolongation of working life might be supported by work-related interventions, focusing on appreciation and the learning environment. Jobs could for example be designed in such a way that persons are continuously stimulated to expand their knowledge and skills and adapt their knowledge and skills to changes in their work. The results of the present study show that the causes of early retirement are multifactorial, which advocates that policies, regulations, and interventions focus on a diversity of factors to prolong working lives.

\section{Acknowledgments}

The current study was conducted with financial support from the Ministry of Social Affairs and Employment in the Netherlands.

\section{References}

1. From work to retirement; persons 55 years or older [Internet]. Den Haag / Heerlen, the Netherlands: Centraal Bureau voor de Statistiek; 2012. Available from: http://statline.cbs.nl/ StatWeb/publication/?VW=T \&DM $=$ SLNL\&PA $=8039$ $6 \mathrm{NED} \& \mathrm{D} 1=1,9 \& \mathrm{D} 2=0 \& \mathrm{D} 3=0 \& \mathrm{D} 4=0 \& \mathrm{D} 5=1 \& \mathrm{D} 6=0$ $1,3-6,9-12,14,17-20 \& \mathrm{D} 7=0 \& \mathrm{D} 8=3,6-11 \& \mathrm{HD}=120111$ $1606 \& H D R=G 4, G 3, G 2, G 1, G 6, T, G 7 \& S T B=G 5$.

2. Van Den Berg TIJ, Elders LAM, Burdorf A. Influence of health and work on early retirement. J Occup Environ Med. 2010;52(6):576-83. http://dx.doi.org/10.1097/ JOM.0b013e3181de8133.

3. Schuring M, Robroek SJ, Otten FW, Arts CH, Burdorf A. The effect of ill health and socioeconomic status on labor force exit and re-employment: A prospective study with ten years follow-up in the Netherlands. Scand J Work Environ Health. 2013; 39(2):134-43. http://dx.doi.org/10.5271/sjweh.3321.

4. Reeuwijk KG, de Wind A, Westerman MJ, Ybema JF, van der Beek AJ, Geuskens GA. 'All those things together made me retire': Qualitative study on early retirement among dutch employees. BMC Publ Health. 2013;13(1):516. http://dx.doi. org/10.1186/1471-2458-13-516.

5. Lund T, Iversen L, Poulsen KB. Work environment factors, health, lifestyle and marital status as predictors of job change and early retirement in physically heavy occupations. Am J Ind Med. 2001;40(2):161-9. http://dx.doi.org/10.1002/ ajim. 1084 .

6. Henkens K, Van Dalen H, Van Solinge H. De vervagende grens tussen werk en pensioen. over doorwerken, doorstarten en herintreders [The fading border between employment and retirement. about continuing to work and re-entering employment]. Den Haag, the Netherlands: NIDI; 2009.

7. Damman M, Henkens K, Kalmijn M. The impact of midlife educational, work, health, and family experiences on men's early retirement. J Gerontol Ser B Psychol Sci Soc Sci. 2011;66 B(5):617-27.

8. Herrbach O, Mignonac K, Vandenberghe C, Negrini A Perceived HRM practices, organizational commitment, and voluntary early retirement among late-career managers. Hum Resour Manage. 2009;48(6):895-915. http://dx.doi. org/10.1002/hrm.20321.

9. Fischer JAV, Sousa-Poza A. The institutional determinants of early retirement in europe. London: Department of Economics, University of St. Gallen; 2006.

10. Pearlin LI, Lieberman MA, Menaghan EG, Mullan JT. The 
stress process. J Health Soc Behav. 1981;22(4):337-56. http:// dx.doi.org/10.2307/2136676.

11. Donaldson T, Earl JK, Muratore AM. Extending the integrated model of retirement adjustment: Incorporating mastery and retirement planning. J Vocat Behav. 2010;77(2):279-89. http:// dx.doi.org/10.1016/j.jvb.2010.03.003.

12. De Wind A, Geuskens GA, Reeuwijk KG, Westerman MJ, Ybema JF, Burdorf A, et al. Pathways through which health influences early retirement: A qualitative study. BMC Publ Health. 2013 Apr 3;13:292. http://dx.doi.org/10.1186/14712458-13-292.

13. Ybema JF, Geuskens GA, Van den Heuvel S. Study on Transitions in Employment, Ability and Motivation (STREAM): methodologie en eerste resultaten [STREM: methodology and primary results]. Hoofddorp, the Netherlands: TNO; 2011.

14. Van Den Berg TIJ, Schuring M, Avendano M, Mackenbach J, Burdorf A. The impact of ill health on exit from paid employment in europe among older workers. Occup Environ Med. 2010;67(12):845-52. http://dx.doi.org/10.1136/ oem.2009.051730.

15. Ware Jr. JE, Kosinski M, Keller SD. A 12-item short-form health survey: Construction of scales and preliminary tests of reliability and validity. Med Care. 1996;34(3):220-33. http:// dx.doi.org/10.1097/00005650-199603000-00003.

16. Koppes L, De Vroome E, Mol M, Janssen B, Van den Bossche S. Nationale enquête arbeidsomstandigheden 2009: Methodologie en globale resultaten [The Netherlands working conditions survey 2009: Methodology and overall results]. Hoofddorp, the Netherlands: TNO; 2010.

17. Hildebrandt VH, Bongers PM, van Dijk FJ, Kemper HC, Dul J. Dutch Musculoskeletal Questionnaire: Description and basic qualities. Ergonomics. 2001 Oct 10;44(12):1038-55. http:// dx.doi.org/10.1080/00140130110087437.

18. Karasek R. Job content questionnaire and user's guide. Lowell: University of Massachusetts, Department of work environment; 1985.

19. Karasek R, Brisson C, Kawakami N, Houtman I, Bongers P, Amick B. The job content questionnaire (JCQ): An instrument for internationally comparative assessments of psychosocial job characteristics. J Occup Health Psychol. 1998;3(4):32255. http://dx.doi.org/10.1037/1076-8998.3.4.322.

20. Koppes L, De Vroome E, Mol M, Janssen B, Van den Bossche S. Nationale enquête arbeidsomstandigheden 2008: Methodologie en globale resultaten [The Netherlands working conditions survey 2008: Methodology and overall results]. Hoofddorp, the Netherlands: TNO; 2009.

21. Kristensen TS, Hannerz H, Høgh A, Borg V. The copenhagen psychosocial questionnaire - A tool for the assessment and improvement of the psychosocial work environment. Scand J Work Environ Health. 2005;31(6):438-49. http://dx.doi. org/10.5271/sjweh.948.

22. COPSOQ II: The scales of the COPSOQ II questionnaire. [Internet]. Available from: http://www.arbejdsmiljoforskning. $\mathrm{dk} / \mathrm{en} /$ publikationer/spoergeskemaer/psykisk-arbejdsmiljoe.
23. Van Veldhoven M, Dorenbosch L. Age, proactivity and career development. Career Development International. 2008;13(2):112 31. http://dx.doi.org/10.1108/13620430810860530.

24. Laaksonen M. Population attributable fraction in epidemiologic follow-up studies. Helsinki, Finland: National Institute for Health and Welfare; 2010.

25. Hennekens CH, Buring JE. Epidemiology in medicine. 1st ed. USA, Philadelphia: Lippincott Williams \& Wilkins; 1987.

26. Crawford R, Tetlow G. Employment, retirement and pensions. In: Banks J, Lessof C, Nazroo J, Rogers N, Stafford M, Steptoe A, editors. Financial circumstances, health and wellbeing of the older population in England - The 2008 English Longitudinal Study of Ageing (Wave 4). London: The Institute for Fiscal Studies; 2010. p. 11-75.

27. Proper KI, Deeg DJH, van der Beek A. Challenges at work and financial rewards to stimulate longer workforce participation. Human Resources for Health. 2009;7:70. http://dx.doi. org/10.1186/1478-4491-7-70.

28. Robroek SJ, Schuring M, Croezen S, Stattin M, Burdorf A. Poor health, unhealthy behaviors, and unfavorable work characteristics influence pathways of exit from paid employment among older workers in europe: A four year follow-up study. Scand J Work Environ Health. 2013 Mar 1;39(2):125-33. http://dx.doi.org/10.5271/sjweh.3319.

29. Future pension system [Internet]. Den Haag, the Netherlands: Rijksoverheid; 2012. Available from: http:// www.rijksoverheid.nl/onderwerpen/pensioen/toekomstpensioenstelsel.

30. Mykletun A, Overland S, Dahl AA, Krokstad S, Bjerkeset O, Glozier N, et al. A population-based cohort study of the effect of common mental disorders on disability pension awards. Am J Psychiatry. 2006 Aug;163(8):1412-8. http://dx.doi. org/10.1176/appi.ajp.163.8.1412.

31. Burdorf A, van der Beek AJ. In musculoskeletal epidemiology are we asking the unanswerable in questionnaires on physical load? Scand J Work Environ Health. 1999 Apr;25(2):81-3. http://dx.doi.org/10.5271/sjweh.409.

32. Miilunpalo S, Vuori I, Oja P, Pasanen M, Urponen H. Selfrated health status as a health measure: The predictive value of self-reported health status on the use of physician services and on mortality in the working-age population. J Clin Epidemiol. 1997;50(5):517-28. http://dx.doi.org/10.1016/ S0895-4356(97)00045-0.

33. Pelletier KR. A review and analysis of the clinical and costeffectiveness studies of comprehensive health promotion and disease management programs at the worksite: Update VII 2004-2008. J Occup Environ Med. 2009 Jul;51(7):822-37. http://dx.doi.org/10.1097/JOM.0b013e3181a7de5a.

34. Cancelliere C, Cassidy JD, Ammendolia C, Cote P. Are workplace health promotion programs effective at improving presenteeism in workers? A systematic review and best evidence synthesis of the literature. BMC Publ Health. 2011 May 26;11:395. http://dx.doi.org/10.1186/1471-2458-11-395.

Received for publication: 26 February 2013 